\title{
Characterization of Erbium Substituted Yttrium Iron Garnet Films Prepared by Sol-Gel Method
}

\author{
Ramadan E. Shaiboub ${ }^{1}$ and N. B. Ibrahim ${ }^{2}$ \\ ${ }^{1}$ Physics Department, Faculty of Education, University of Algabel Alghrbi, Nalut, Libya \\ ${ }^{2}$ School of Applied Physics, Faculty of Science and Technology, Universiti Kebangsaan Malaysia, 43600 Bangi, Selangor, Malaysia
}

Correspondence should be addressed to Ramadan E. Shaiboub; ame1642001@yahoo.com

Received 21 November 2013; Revised 4 March 2014; Accepted 13 March 2014; Published 6 April 2014

Academic Editor: Stephane Daniele

Copyright $\odot 2014$ R. E. Shaiboub and N. B. Ibrahim. This is an open access article distributed under the Creative Commons Attribution License, which permits unrestricted use, distribution, and reproduction in any medium, provided the original work is properly cited.

\begin{abstract}
Yttrium iron garnet (YIG) thin films substituted erbium ions $\left(\mathrm{Er}^{+3}\right) \mathrm{Er}_{04} \mathrm{Y}_{26} \mathrm{Fe}_{5} \mathrm{O}_{12}$ films were prepared by a sol-gel method at different temperatures which varied from 800 to $1000^{\circ} \mathrm{C}$ for 2 hours in air. Magnetic and microstructural properties of the films were characterized with X-ray diffraction (XRD), the field emission scanning electron microscopy (FESEM), and vibrating sample magnetometer (VSM). The XRD patterns of the sample have only peaks of the garnet structure. The lattice constants decrease, while the particle size increases from 51 to $85 \mathrm{~nm}$ as the annealing temperature increases with average in thickness of $300 \mathrm{~nm}$. The saturation magnetization and the coercivity of the samples increased from $26(\mathrm{emu} / \mathrm{cc})$ and 28 Oe for the film annealed at $800^{\circ} \mathrm{C}$ to $76(\mathrm{emu} / \mathrm{cc})$ and $45 \mathrm{Oe}$ for film annealed at $1000^{\circ} \mathrm{C}$, respectively.
\end{abstract}

\section{Introduction}

The study of yttrium iron garnet (YIG) thin films is becoming more important because of properties that can be extensively used in optical communication [1], magneto-optical devices, and applied in microwave [2]. YIG is the most representative and well-known compound among the rareearth garnets and various magnetizations can be achieved by substitution process. Thin and thick films have been produced in garnets using different methods such as liquid phase epitaxy, sputtering, chemical vapor deposition, liquid phase epitaxy, laser ablation, and sol-gel. In recent years, sol-gel methods have attracted much attention due to use of lower synthetic temperature to produce finer and more homogeneous particles. The sol-gel synthetic method has been widely used to prepare nanostructured films and can be used to systematically vary the chemical composition of target compounds over pulsed laser deposition and sputtering techniques which are also compatible with the fabrication of nanoscaled thin films. So in this study, sol-gel method is used to achieve homogeneous systems with respect to the desired metals. YIG is a ferromagnetic material and it has a cubic structure with a space group Ia3d with the general unit formula $\left(\mathrm{Y}_{3} \mathrm{Fe}_{5} \mathrm{O}_{12}\right)$ [3]. The magnetic ions are distributed over three crystallographic sites with sublattice magnetization $\mathrm{Ma}$ [octahedral site, $16 \mathrm{Fe}^{3+}$ ions in a], $M d$ (tetrahedral site, $24 \mathrm{Fe}^{3+}$ ions in $\mathrm{d}$ ), and $M c$ (dodecahedral site, $24 \mathrm{Y}^{3+}$ ions in $\mathrm{c}\}$. Ionic distribution in garnet is represented as $\left\{\mathrm{Y}_{3}^{3+}\right\}\left[\mathrm{Fe}_{2}^{3+}\right]\left(\mathrm{Fe}_{3}^{3+}\right) \mathrm{O}_{12}{ }^{2-}$. The interaction between the $\mathrm{Fe}^{3+}$ ions in [a] and (d) sites is strongly antiferromagnetic due to strong superexchange interaction. The magnetic moment of the rare-earth ions in the $\{c\}$ sublattice couples antiparallel with the resultant moment of $\mathrm{Fe}^{3+}$ ions. In a YIG system, nonmagnetic $\mathrm{Y}^{3+}$ ions occupy dodecahedral $\{c\}$ sites and magnetic $\mathrm{Fe}^{3+}$ ions occupy octahedral [a] and tetrahedral (d) sites. The magnetic moment caused by two $\mathrm{Fe}^{3+}$ ions in [a] site is aligned antiparallel to that caused by three $\mathrm{Fe}^{3+}$ ions in (d) site, leaving a net moment from $\mathrm{Fe}^{3+}$ in the d-site. Therefore, the saturation magnetization of YIG is given by the magnetic $\mathrm{Fe}^{3+}$ in the d-sites. The paramagnetic trivalent $\mathrm{Er}^{3+}$ ions can be substituted for nonmagnetic $\mathrm{Y}^{3+}$ ions in \{c\} sites, but not for $\mathrm{Fe}^{3+}$ ions in [a] or (d) sites [4]. The magnetic moment of $\mathrm{Er}^{3+}$ substituted for $\mathrm{Y}^{3+}$ in $\{\mathrm{c}\}$ sites, 
which can be parallel to the magnetic moment of $\mathrm{Fe}^{3+}$ in the $\mathrm{d}$-sites, meaning that the saturation magnetization of Er:YIG is different from that of pure YIG. A number of researches have been done in substituting $\mathrm{Bi}^{3+}, \mathrm{Ce}^{3+}$ for $\mathrm{Y}^{3+}$ and $\mathrm{Co}^{3+}$, $\mathrm{Co}^{2+}$ for $\mathrm{Fe}^{3+}$ in YIG [5-12]. However, some works have been carried out to study Er-YIG powder nanoparticles [13-20] and few in thin film form. Erbium is chosen because its ionic radius (1.03 $\AA$ ) is slightly less than ionic radius of yttrium $(1.04 \AA)$. Also, it has an extremely high verdet constant at $(\lambda=600 \mathrm{~nm})$ and large Bohr magneton $(9.6 \mu \mathrm{B})$ [21]. This paper focuses on the influence of low concentration of $\mathrm{Er}^{+3}$ ions substituted YIG thin films $\left(\mathrm{Er}_{0.4} \mathrm{Y}_{2.6} \mathrm{Fe}_{5} \mathrm{O}_{12}\right)$ at different annealing temperatures.

\section{Experimental}

The Er:YIG precursor sol was prepared by sol-gel method using reagent grade nitrates purchased from Aldrich, Milwaukee, WI, USA. Yttrium nitrate hexahydrate $\left[\mathrm{Y}\left(\mathrm{NO}_{3}\right)_{3} \cdot 6 \mathrm{H}_{2} \mathrm{O}, 99.95 \%\right.$ purity], iron (III) nitrate nanohydrate $\left[\mathrm{Fe}\left(\mathrm{NO}_{3}\right)_{3} \cdot 9 \mathrm{H}_{2} \mathrm{O}, 98+\%\right.$ purity], and erbium nitrate pentahydrate $\left[\mathrm{Er}\left(\mathrm{NO}_{3}\right)_{3} \cdot 5 \mathrm{H}_{2} \mathrm{O}, 99.9 \%\right.$, metals basis] were used as raw materials. 2-Methoxyethanol and acetic acid were used as solvents. $\mathrm{Fe}\left(\mathrm{NO}_{3}\right)_{3} \cdot 9 \mathrm{H}_{2} \mathrm{O}$ and $\mathrm{Y}\left(\mathrm{NO}_{3}\right)_{3} \cdot 6 \mathrm{H}_{2} \mathrm{O}$ were dissolved in the 2-methaxythanol and refluxed at $80^{\circ} \mathrm{C}$ for 3 hours. The $\mathrm{Er}\left(\mathrm{NO}_{3}\right)_{3} \cdot 5 \mathrm{H}_{2} \mathrm{O}$ dissolved in acetic acid was added gradually into the $\mathrm{Fe}-\mathrm{Y}$ solution. Then the refluxing process was carried out for 3 hours. A small quantity of diethylamine was added to the mixture solution, while the $\mathrm{pH}$ value was adjusted in the range of 2-3. After cooling down to room temperature, the solution was stirred for 3 days. The gel was transformed into thin film form (onto quartz substrates) using the spin coating technique. The rate of the spinning process was $3500 \mathrm{rpm}$ and it was done for 30 second. After the spinning process, the films were heated at $90^{\circ} \mathrm{C}$ for 2 hours to remove the residual solvents and then at $350^{\circ} \mathrm{C}$ for $15 \mathrm{~min}$ at a heating rate of $3^{\circ} \mathrm{C} / \mathrm{min}$ to burn off the organic materials, followed by annealing process at 800,900 , and $1000^{\circ} \mathrm{C}$ for 2 hours at a heating rate of $4^{\circ} \mathrm{C} / \mathrm{min}$ to crystallize them as shown in Figure 1 . The X-ray diffractions were done at $2 \theta=20^{\circ}$ to $80^{\circ}$ to investigate the structural properties of the films. Magnetic measurements were carried out at room temperature using a vibrating sample magnetometer (VSM). The field emission scanning electron microscope (FESEM) was carried out at the magnification of $300,000 x$ to examine the surface quality of the films.

\section{Result and Discussions}

3.1. X-Ray Diffraction Measurements. Figure 2 shows the XRD spectra for $\mathrm{Er}_{0.4} \mathrm{Y}_{2.6} \mathrm{Fe}_{5} \mathrm{O}_{12}$ films annealed at 800$1000^{\circ} \mathrm{C}$ for 2 hours. All of the samples show single phases of the garnet structure with diffraction lines (hkl) corresponding to the cubic garnet structure. We obtained the single garnet phase at $800^{\circ} \mathrm{C}$ due to the good homogeneity of the gel prepared at $\mathrm{pH}=2-3$, while the single garnet phase of $\mathrm{Er}_{x} \mathrm{Y}_{3-x} \mathrm{Fe}_{5} \mathrm{O}_{12}(0 \leq x \leq 1.0)$ prepared by [22] was obtained

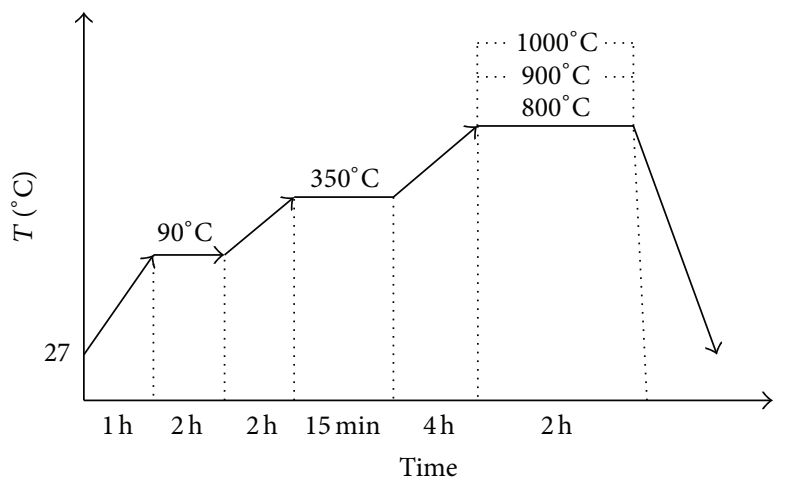

FIGURE 1: The flowchart of the heat treatment process.

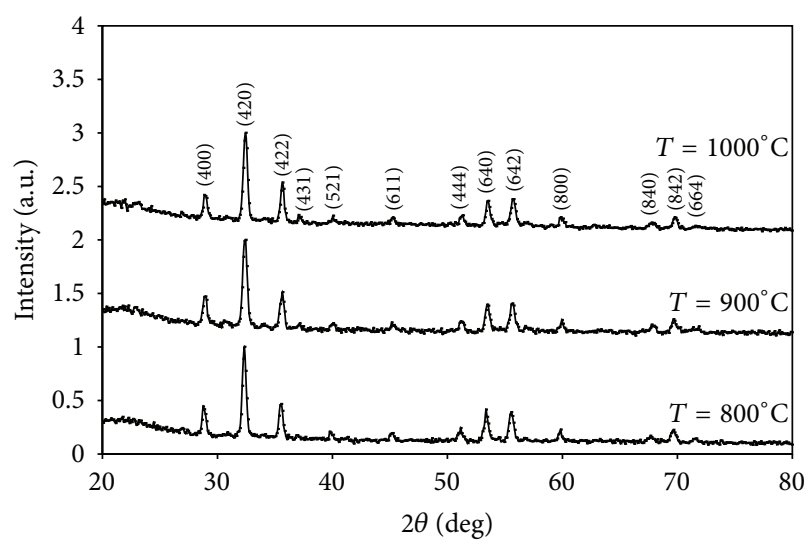

FIgURE 2: The XRD patterns of $\mathrm{Er}_{0.4} \mathrm{Y}_{2.6} \mathrm{Fe}_{5} \mathrm{O}_{12}$ films annealed for $2 \mathrm{~h}$ at different temperatures.

at $850^{\circ} \mathrm{C}$. The values of lattice constant of the films calculated from the XRD pattern were in the range of 12.339 to $12.359 \AA$ and were found a little smaller than the pure YIG (12.376 $\AA$ )

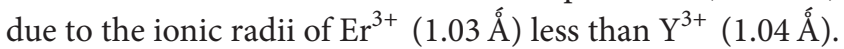
The effect of the heat treatment has been studied by several researches. They observed that the lattice parameter decreases with increasing heat treatment temperature [23]. The average lattice constants values of $\mathrm{Er}_{0.4} \mathrm{Y}_{2.6} \mathrm{Fe}_{5} \mathrm{O}_{12}$ films as a function of different annealing temperatures are shown in Table 1.

3.2. Microstructural Properties. The microstructures of all of the $\mathrm{Er}_{0.4} \mathrm{Y}_{2.6} \mathrm{Fe}_{5} \mathrm{O}_{12}$ films were studied using field emission scanning electron microscope (FESEM) as shown in Figures 3(a)-3(c). The particle size obtained for these samples increases with the annealing temperature increased. From the images of the FESEM micrograph, the resulting grains show that the particles stuck to each other when the annealing temperature is above $800^{\circ} \mathrm{C}$ and this implies that the particles are highly agglomerate due to their high surface energy [24]. The micrographs show that the particles stuck together, and these hard agglomerates are called aggregates. Agglomeration of fine particles can occur at the synthesis stage, during drying and subsequent processing of the particles. Agglomeration of fine particles is caused by the attractive van der Waals 
TABLE 1: The variation of annealing temperature with the coercivity $(\mathrm{Hc})$, magnetization $\left(M_{s}\right)$, particle size, and lattice constants.

\begin{tabular}{lcccc}
\hline Annealing temp. $\left({ }^{\circ} \mathrm{C}\right)$ & $\mathrm{Hc}(\mathrm{Oe})$ & $M_{s}(\mathrm{emu} / \mathrm{cc})$ & Average particle size $(\mathrm{nm})$ & Average lattice constants $(\AA)$ \\
\hline 800 & 28 & 26 & 51 & 12.359 \\
900 & 36 & 60 & 59 & 12.358 \\
1000 & 45 & 76 & 85 & 12.339 \\
\hline
\end{tabular}
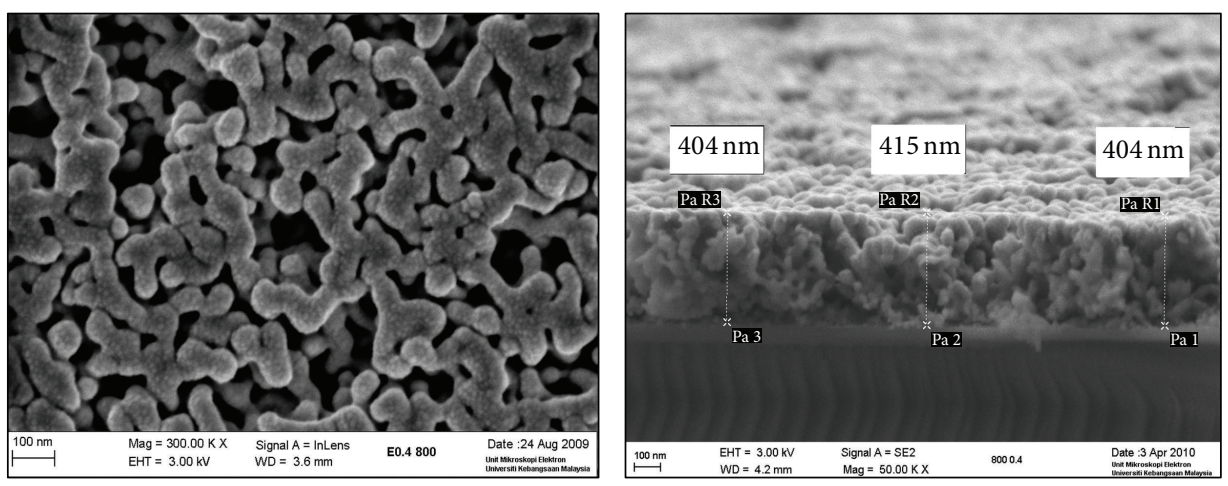

(a)
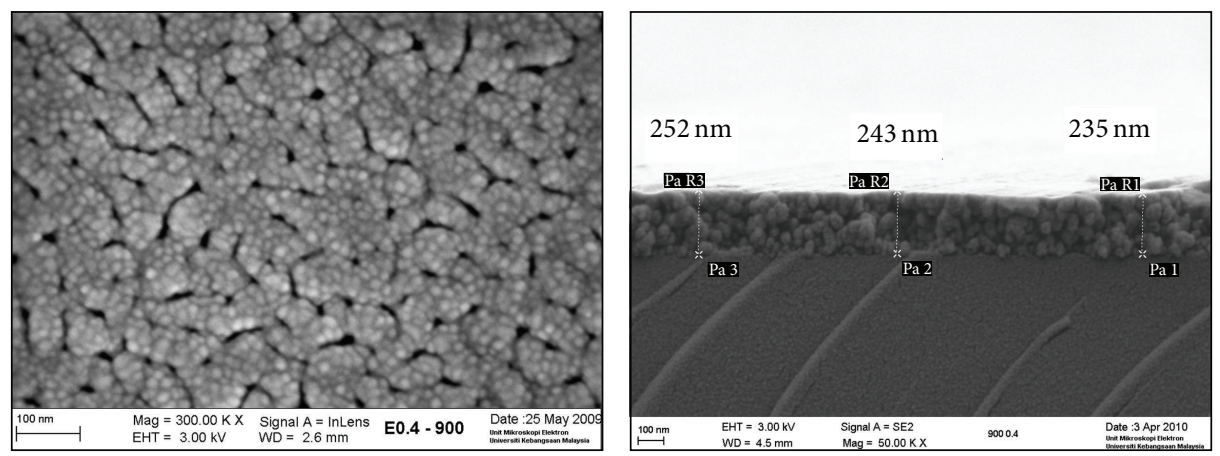

(b)
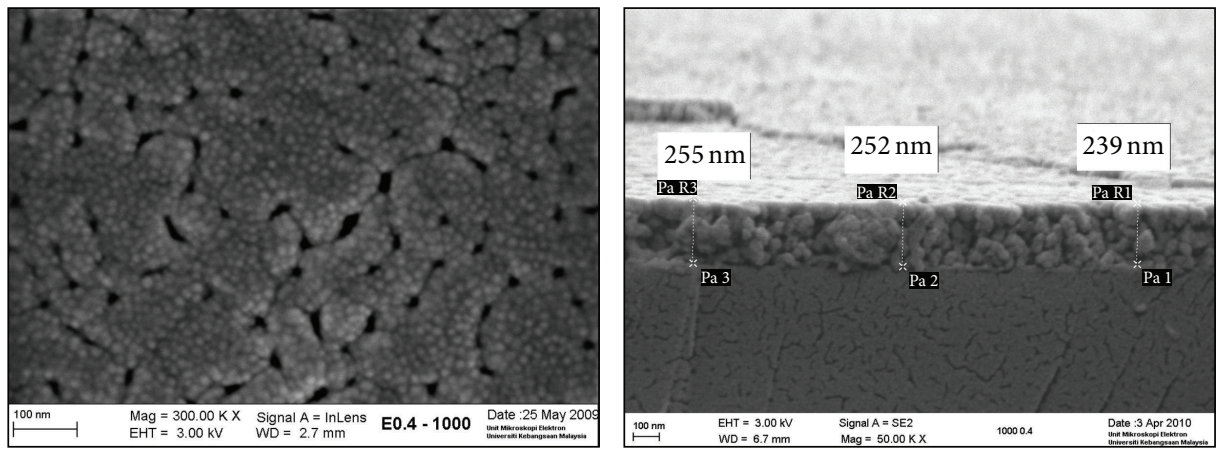

(c)

Figure 3: FE-SEM micrograph and images of cross-section of $\mathrm{Er}_{0.4} \mathrm{Y}_{2.6} \mathrm{Fe}_{5} \mathrm{O}_{12}$ films at different annealing temperatures: (a) $800^{\circ} \mathrm{C}$, (b) $900^{\circ} \mathrm{C}$, and (c) $1000^{\circ} \mathrm{C}$.

force and the driving force that tends to minimize the total surface energy of the system. The grains could not be seen clearly, and this may be because of masking caused by the gold coating on the film's surface. The thicknesses of the films were decreased as the annealing increased and ranged from $408 \mathrm{~nm}$ to $249 \mathrm{~nm}$. We can conclude that for different annealing temperatures, the crystallite sizes of $\mathrm{Er}_{0.4} \mathrm{Y}_{2.6} \mathrm{Fe}_{5} \mathrm{O}_{12}$ films are increased, while the films thicknesses were reduced. This is probably due to the different ionic radius of $\mathrm{Er}^{3+}(1.03 \AA$ A $)$ which is less than $\mathrm{Y}^{3+}(1.04 \AA)$ ), which leads to some apparent variation about the crystalline lattice.

3.3. Magnetic Properties. The magnetic properties of the samples at different annealing temperatures of $\mathrm{Er}_{0.4} \mathrm{Y}_{2.6} \mathrm{Fe}_{5} \mathrm{O}_{12}$ 


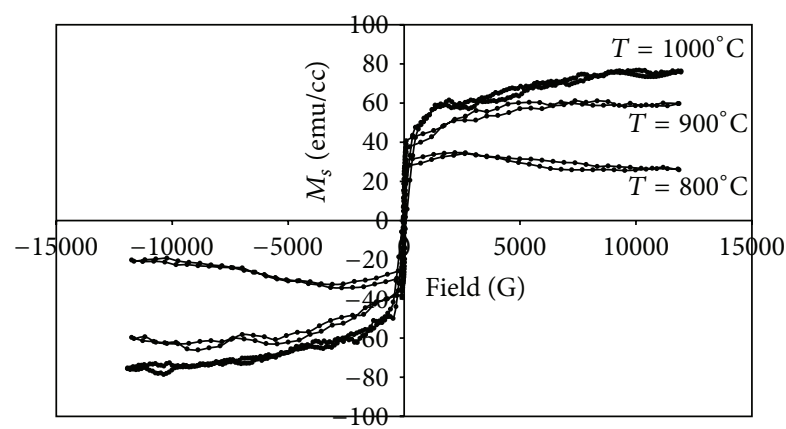

Figure 4: The in-plane hysteresis loop for $\mathrm{Er}_{0.4} \mathrm{Y}_{2.6} \mathrm{Fe}_{5} \mathrm{O}_{12}$ films annealed for $2 \mathrm{~h}$ at different annealing temperatures.

films were measured using vibration samples magnetometer (VSM) with a maximum applied field of $12 \mathrm{kOe}$ at room temperature. Figure 4 shows the in-plane magnetization properties and typical hysteresis loop for all films. The hysteresis curves indicate that $\mathrm{Er}_{0.4} \mathrm{Y}_{2.6} \mathrm{Fe}_{5} \mathrm{O}_{12}$ films annealed at 800 to $1000^{\circ} \mathrm{C}$ are soft magnetic materials. The saturation magnetization $\left(M_{s}\right)$ of the films increased from $26(\mathrm{emu} / \mathrm{cc})$ for the film annealed at $800^{\circ} \mathrm{C}$ to $76(\mathrm{emu} / \mathrm{cc})$ for film annealed at $1000^{\circ} \mathrm{C}$ when the particle size increased from 51 to $85 \mathrm{~nm}$ as shown in Table 1 and Figures 5(a) and 5(b). This rise can be related to the higher surface-to-volume ratio in the smaller particles, which results in the existence of nonmagnetization surface layer. Also the $M_{s}$ of the particles decreases as the particle sizes reduce due to the enhancement of the surface spin effects. The coercivity $(\mathrm{Hc})$ increased from 28 to $45 \mathrm{Oe}$ as the temperature rose to $1000^{\circ} \mathrm{C}$ as shown in (Figure 5(c)).

\section{Conclusion}

We have studied the synthesis of YIG substituted $\left(\mathrm{Er}^{+3}\right)$ $\mathrm{Er}_{0.4} \mathrm{Y}_{2.6} \mathrm{Fe}_{5} \mathrm{O}_{12}$ nanoparticles, with size between 51 and $85 \mathrm{~nm}$ at different temperatures varied from 800 to $1000^{\circ} \mathrm{C}$ prepared using a sol-gel method. The results show that, at low concentration of $\mathrm{Er}^{3+}$ ion, the best annealing temperature for crystallinity begins at $800^{\circ} \mathrm{C}$. From the XRD, it can be observed that all the samples have only a single phase of garnet structure. The average values of lattice constants of the films were decreased as the temperature increased. The particle size obtained for these samples increases with the annealing temperature increasing and the particles are highly agglomerate due to their high surface energy. The saturation magnetization $\left(M_{s}\right)$ decreases as the particle size is reduced due to the enhancement of the surface spin effects. The thicknesses of these samples reduced as the annealing rises to $1000^{\circ} \mathrm{C}$.

\section{Conflict of Interests}

The authors declare that there is no conflict of interests regarding the publication of this paper.

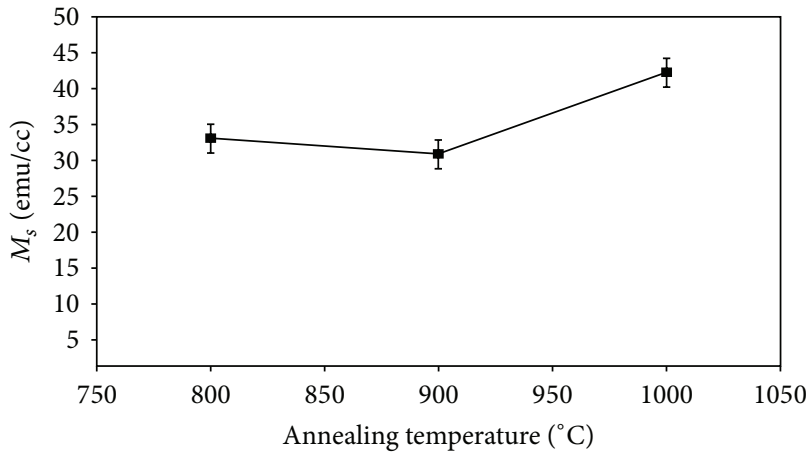

(a)

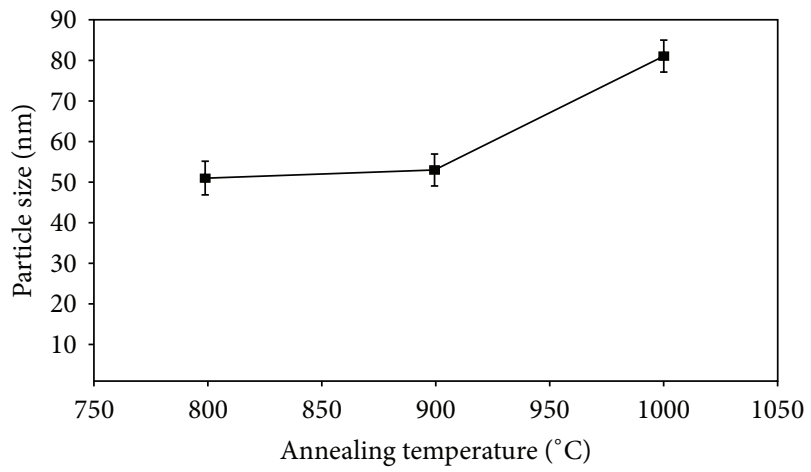

(b)

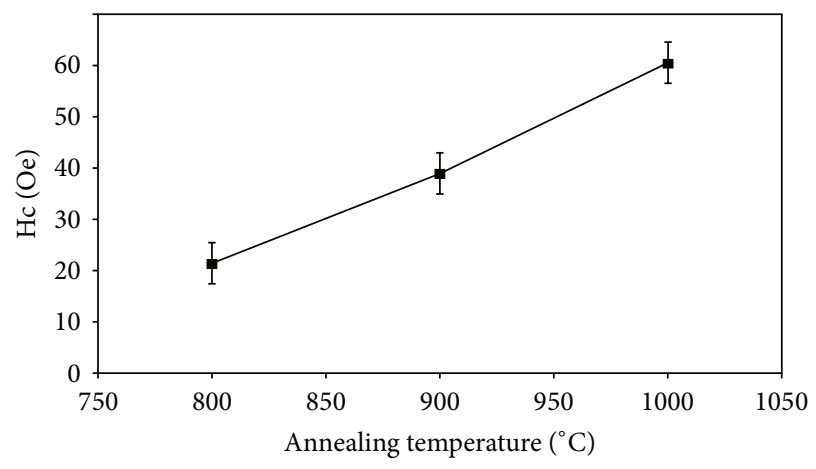

(c)

FIGURE 5: The variation of (a) saturation magnetization, (b) particle size, and (c) coercivity with different annealing temperatures.

\section{Acknowledgment}

The authors would like to thank the University Kebangsaan Malaysia for the help in providing the instruments and the analytical techniques which are used in this work.

\section{References}

[1] A. V. Nazarov, D. Ménard, J. J. Green, C. E. Patton, G. M. Argentina, and H. J. van Hook, "Near theoretical microwave loss in hot isostatic pressed (hipped) polycrystalline yttrium iron garnet," Journal of Applied Physics, vol. 94, no. 11, pp. 7227-7234, 2003.

[2] T. Aichele, A. Lorenz, R. Hergt, and P. Görnert, "Garnet layers prepared by liquid phase epitaxy for microwave and 
magneto-optical applications-a review," Crystal Research and Technology, vol. 38, no. 7-8, pp. 575-587, 2003.

[3] S. Geller and M. A. Gilleo, "The crystal structure and ferrimagnetism of yttrium-iron garnet, $\mathrm{Y}_{3} \mathrm{Fe}_{2}\left(\mathrm{FeO}_{4}\right)_{3}$," Journal of Physics and Chemistry of Solids, vol. 3, no. 1-2, pp. 30-36, 1957.

[4] M. S. Lataifeh and A. al-sharif, "Magnetization measurements on some rare-earth iron garnets," Applied Physics A: Materials Science \& Processing, vol. 61, no. 4, pp. 415-418, 1995.

[5] M. Gomi, K. Satoh, and M. Abe, "New garnet films with giant Faraday rotation," in Proceedings of the 5th International Conference on Ferrites, pp. 919-924, Bombay, India, 1989.

[6] T. Shintaku and T. Uno, "Preparation of Ce-substituted yttrium iron garnet films for magneto-optic waveguide devices," Japanese Journal of Applied Physics, vol. 35, no. 9, pp. 4689-4691, 1996.

[7] A. Tate, T. Uno, S. Mino, A. Shibukawa, and T. Shintaku, "Crystallinity of Ce-substituted YIG films prepared by RF sputtering," Japanese Journal of Applied Physics, vol. 35, no. 6, pp. 3419-3425, 1996.

[8] T. Shintaku, A. Tate, and S. Mino, "Ce-substituted yttrium iron garnet films prepared on $\mathrm{Gd}_{3} \mathrm{Sc}_{2} \mathrm{Ga}_{3} \mathrm{O}_{12}$ garnet substrates by sputter epitaxy," Applied Physics Letters, vol. 71, no. 12, pp. 1640$1642,1997$.

[9] C.-Y. Tsay, C.-Y. Liu, K.-S. Liu, I.-N. Lin, L.-J. Hu, and T.-S. Yeh, "Low temperature sintering of microwave magnetic garnet materials," Journal of Magnetism and Magnetic Materials, vol. 239, no. 1-3, pp. 490-494, 2002.

[10] H. Hayashi, S. Iwasa, N. J. Vasa et al., "Fabrication of Bi-doped YIG optical thin film for electric current sensor by pulsed laser deposition," Applied Surface Science, vol. 197-198, pp. 463-466, 2002.

[11] M. Huang and S.-Y. Zhang, "Growth and characterization of cerium-substituted yttrium iron garnet single crystals for magneto-optical applications," Applied Physics A: Materials Science and Processing, vol. 74, no. 2, pp. 177-180, 2002.

[12] M. C. Sekhar, J.-Y. Hwang, M. Ferrera et al., "Strong enhancement of the Faraday rotation in Ce and Bi comodified epitaxial iron garnet thin films," Applied Physics Letters, vol. 94, no. 18, Article ID 181916, 2009.

[13] N. I. Tsidaeva, "The magneto-optical activity of rare-earth ion in Y-substituted erbium and neodymium iron garnets," Journal of Alloys and Compounds, vol. 408-412, pp. 164-168, 2006.

[14] J. Ostoréro and M. Guillot, "High field induced magnetic anisotropy of Al-substituted erbium iron garnet single crystals," IEEE Transactions on Magnetics, vol. 37, no. 4, pp. 2441-2444, 2001.

[15] P. Novák, V. A. Borodin, V. D. Doroshev, M. M. Savosta, and T. N. Tarasenko, "NMR of ${ }^{57} \mathrm{Fe}$ in erbium-yttrium iron garnets," Hyperfine Interactions, vol. 59, no. 1-4, pp. 427-430, 1990.

[16] P. Feldmann, M. Guillot, H. le Gall, and A. Marchand, "Faraday rotation in erbium-yttrium iron garnet," IEEE Transactions on Magnetics, vol. 17, no. 6, pp. 3217-3219, 1981.

[17] N. Tsidaeva and V. Abaeva, "The investigation of mechanisms of the magneto-optical activity of rare-earth iron garnet single crystals," Journal of Alloys and Compounds, vol. 418, no. 1-2, pp. 145-150, 2006.

[18] P. Feldmann, H. le Gall, M. Guillot, and A. Marchand, "Anisotropy of the Faraday rotation in erbium-yttrium iron garnet below the compensation temperature," Journal of Applied Physics, vol. 53, no. 3, pp. 2486-2488, 1982.
[19] J. Ostoréro and M. Guillot, "Magnetooptical properties of Sc-substituted erbium-iron-garnet single crystals," Journal of Applied Physics, vol. 83, no. 11, pp. 6756-6758, 1998.

[20] P. Feldmann, H. le Gall, J. M. Desvignes, M. Guillot, and A. Marchand, "Faraday rotation in single crystal erbium iron garnet," Journal of Magnetism and Magnetic Materials, vol. 21, no. 3, pp. 280-284, 1980.

[21] A. di Biccari, Sol-gel processing of RxY3-xAlyFe5-yO12 magnetooptical films [M.S. thesis], Materials Science \& Engineering Department, Blacksburg, Va, USA, 2002.

[22] H. Xu, H. Yang, and L. Lu, "Effect of erbium oxide on synthesis and magnetic properties of yttrium-iron garnet nanoparticles in organic medium," Journal of Materials Science: Materials in Electronics, vol. 19, no. 6, pp. 509-513, 2008.

[23] H. G. Beh, R. Irmawati, Y. Noorhana, and K. P. Lim, "Phase evolution and crystallite size of La-substituted YIG at different calcination temperatures," International Journal of Engineering and Technology, vol. 9, no. 9, pp. 261-265, 2009.

[24] S. Verma, S. D. Pradhan, R. Pasricha, S. R. Sainkar, and P. A. Joy, "A novel low-temperature synthesis of nanosized NiZn ferrite," Journal of the American Ceramic Society, vol. 88, no. 9, pp. 25972599, 2005. 

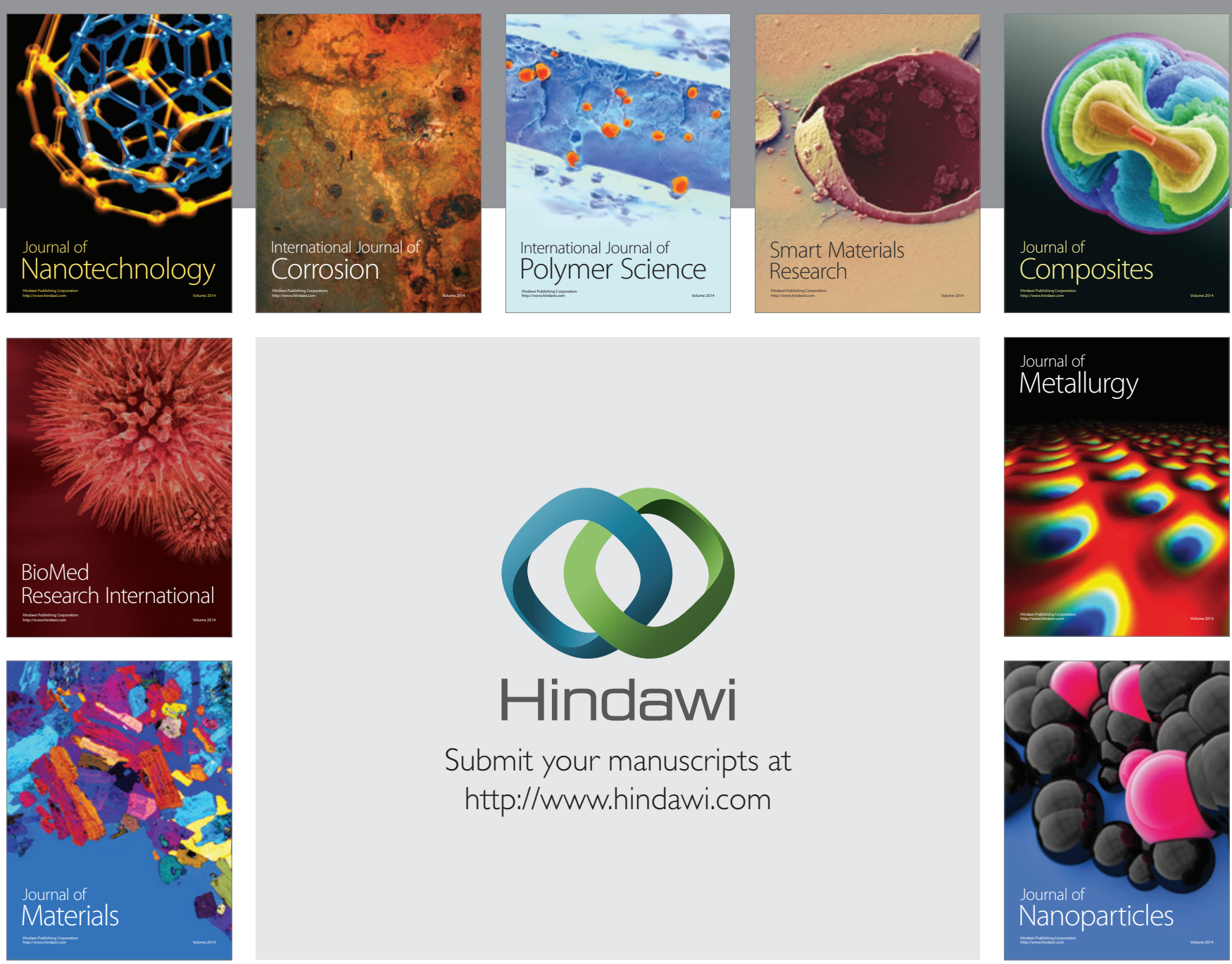

Submit your manuscripts at http://www.hindawi.com
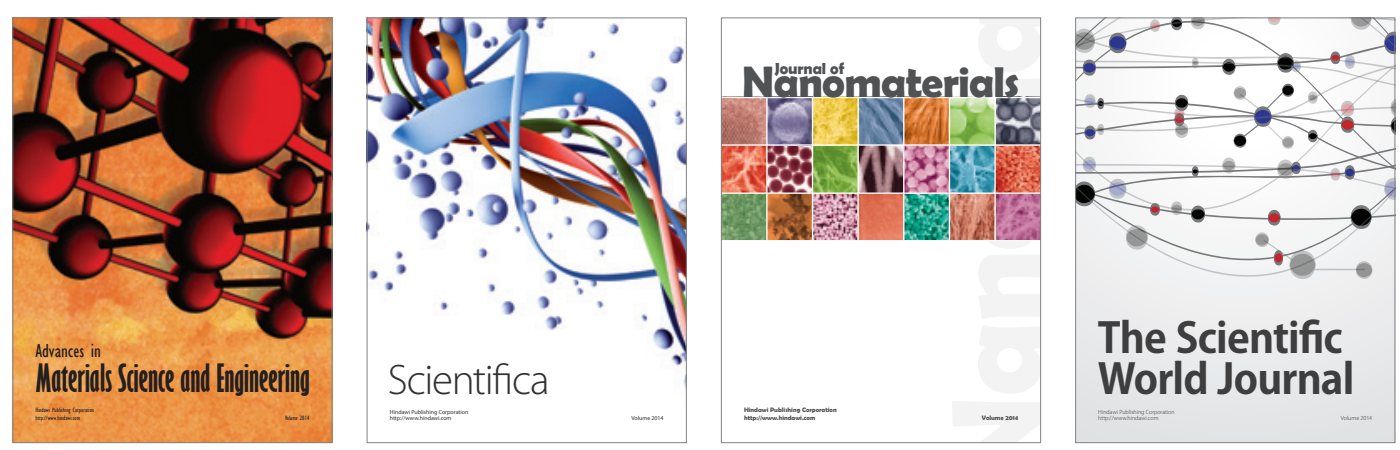

\section{The Scientific World Journal}
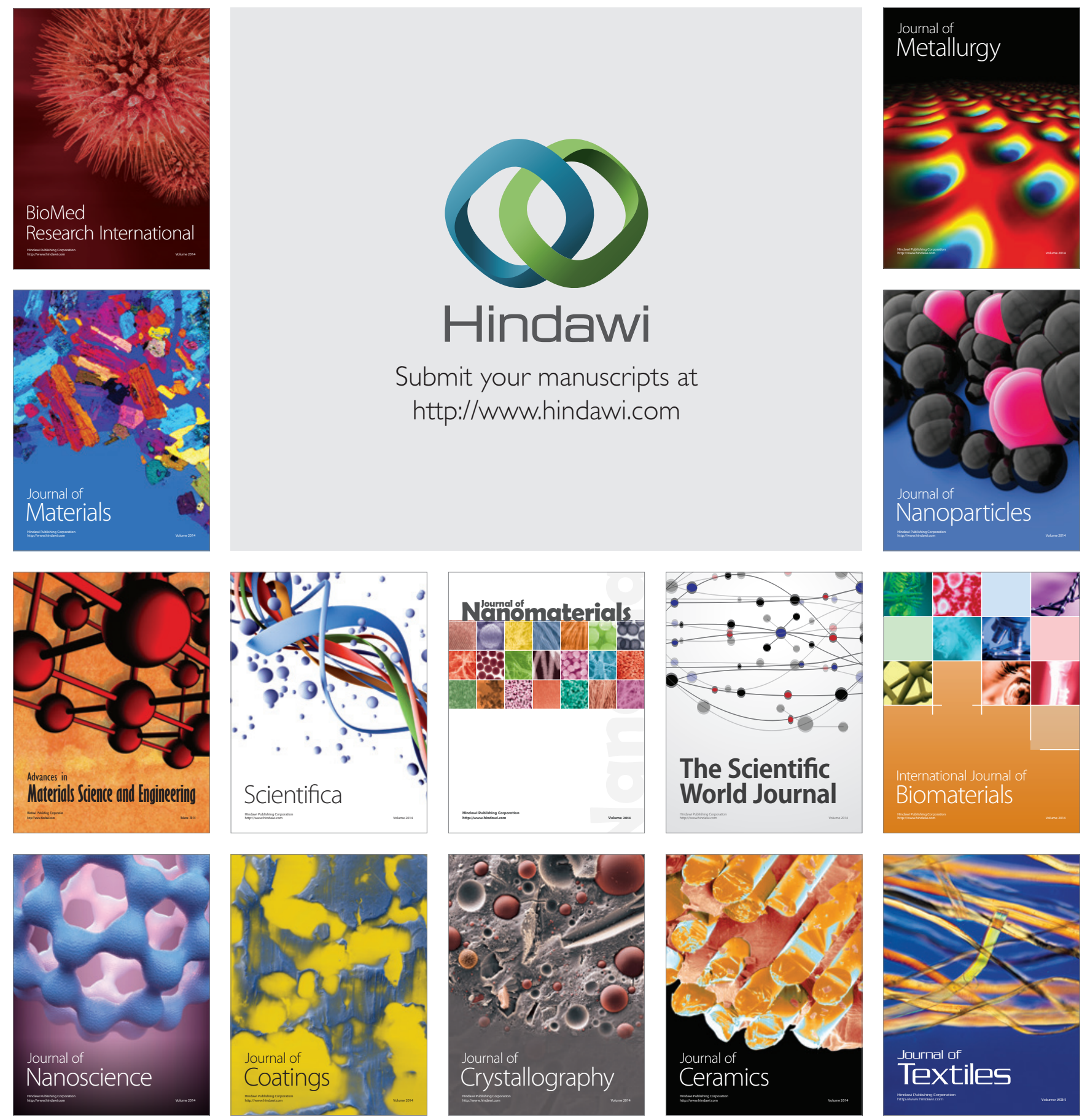